Tarbawy : Jurnal Pendidikan Islam

ISSN : 2407-4462 (Cetak), 2614-5812 (Elektronik)

Vol. 7, No. 2, 2020, Hal. 137-142

DOI: https://doi.org/ 10.32923/tarbawy.v7i2.1446

\title{
Analisis Kesalahan Penulisan Kata (Akhtho' Imlaiyyah) Pada Tulisan Mahasiswa Prodi Pai Iain Sas Bangka Belitung
}

\author{
Ela Isnani Munawwaroh ${ }^{1}$ \\ ${ }^{1}$ IAIN Syaikh Abdurrahman Siddik Bangka Belitung
}

\author{
Info Artikel : \\ Diterima 12 September 2020 \\ Direvisi 16 september 2020 \\ Dipublikasikan 26 Oktober 2020
}

\section{Kata Kunci:}

Akhtha' Imlaiyyah

Kesalahan berbahasa

\begin{abstract}
Tahsinul Kitabah is one of the compulsory courses for the students of the islamic education program at IAIN Syaikh Abdurrahman Siddik Bangka Belitung. At the last of the first semester, I found that the students had many difficulties in writing the Arabic language. Based on that, I wanted to identify the mistakes in the student's writing. In Arabic science, the mistakes are called by akhtho' imlaiyyah. For this research, I used a qualitative approach and a descriptive method. And for collecting the data, I used observation, documentation, and interview method. The result of this research is the mistakes of student's of Islamic education program class $A, B, C$, and $F$ for the first semester of 2019/2020 school year writing in Arabic is about hijaiyah writing, ta' marbuthah and ta' maftuhah, short and length of words, identification of the sound of hijaiyah letter, writing words that have tanwin and tasydid, stringing the letters, and alif lam syamsiah. That's all is be caused by the linguistic's aspect and non linguistic's aspects.
\end{abstract}

\begin{abstract}
Tahsinul Kitabah is one of the compulsory courses for the students of the islamic education program at IAIN Syaikh Abdurrahman Siddik Bangka Belitung. At the last of the first semester, I found that the students had many difficulties in writing the Arabic language. Based on that, I wanted to identify the mistakes in the student's writing. In Arabic science, the mistakes are called by akhtho' imlaiyyah. For this research, I used a qualitative approach and a descriptive method. And for collecting the data, I used observation, documentation, and interview method. The result of this research is the mistakes of student's of Islamic education program class $A, B, C$, and $F$ for the first semester of 2019/2020 school year writing in Arabic is about hijaiyah writing, ta' marbuthah and ta' maftuhah, short and length of words, identification of the sound of hijaiyah letter, writing words that have tanwin and tasydid, stringing the letters, and aliflam syamsiah. That's all is be caused by the linguistic's aspect and non linguistic's aspects.
\end{abstract}

This is an open access article distributed under the Creative Commons Attribution License, which permits unrestricted use, distribution, and reproduction in any medium, provided the original work is properly cited. (C2019 by author.

\section{Koresponden:}

Ela Isnani Munawwaroh,

Email: elaisnani@iainsasbabel.ac.id

\section{Pendahuluan}

Tahsinul Kitabah merupakan salah satu mata kuliah dasar yang diajarkan pada Program Studi (Prodi) Pendidikan Agama Islam (PAI). Setidaknya ada beberapa hal yang menjadikan mata kuliah tersebut penting untuk diajarkan. Pertama, tidak bisa dipungkiri bahwa lulusan SLTA yang masuk ke IAIN Syaikh Abdurrahman Siddik (SAS) Bangka Belitung (khususnya) berasal dari sekolah umum yang kemungkinan mereka pernah belajar ilmu agama khususnya terkait tulis menulis bahasa Arab sangat kecil. Kedua, sebagai calon guru PAI, sudah menjadi kewajiban mereka untuk memiliki kemampuan menulis bahasa Arab dengan baik dan benar. Ketiga, IAIN dengan label kampus Islam sudah sewajarnya menghasilkan sarjana yang unggul dalam bidang agama Islam, dan menulis bahasa Arab adalah bagian dasar dari pengetahuan agama yang harus dimiliki oleh lulusan IAIN.

Dikatakan bahwa untuk mengembangkan kemampuan menulis (maharah al-kitabah) bahasa Arab, dibutuhkan penguasaan sistem bahasa Arab yang meliputi pengetahuan mengenai kosakata (mufrodat), tata bahasa (qowa'id) bahasa Arab sehingga tulisan itu dapat dipahami (Hamid, 2010). Namun hal tersebut belum bisa terpenuhi oleh mahasiswa yang penulis teliti dikarenakan hampir $50 \%$ dari mereka merupakan lulusan sekolah umum. Selain itu, mahasiswa yang merupakan lulusan dari sekolah agama juga masih banyak yang memiliki kemampuan terbatas dalam menulis tulisan Arab. 
Penelitian sebelumnya yang ditulis oleh Barid Syamsiah menyebutkan beberapa jenis kesalahan yang dilakukan oleh mahasiswa IAIN Salatiga di antaranya kesalahan dalam penulisan hamzah qoth' dan hamzah washl,alif layyinah, harakat tanwin, ta' marbuthah, dan huruuf mad. Lebih lanjut, ia menjelaskan bahwa penyebab banyaknya kesalahan mahasiswa dalam imla' tersebut adalah karena ketidaktahuan mereka terkait kaidah-kaidah penulisan tulisan Arab dan juga banyaknya mahasiswa yang berasal dari sekolah umum. (Syamsiyah, 2019). Namun pada mahasiswa yang penulis teliti, terdapat aspek lain yang belum dibahas oleh penelitian sebelumnya, yaitu kesalahan dalam menulis bentuk huruf hijaiyah dan ukuran antar huruf yang tidak seimbang sehingga kesalahan dalam aspek ini bisa menyebabkan kekeliruan lainnya, yaitu kekeliruan dalam membaca tulisan Arab.

Oleh karena itu, agar bisa melihat bagaimana hasil pembelajaran mahasiswa lebih lanjut khususnya terkait dengan kemampuan menulis tulisan Arab, penulis mencoba melakukan penelitian kemampuan menulis mahasiswa khususnya pada kelas PAI semester I kelas A, B, C dan F. Untuk menghasilkan data yang berkaitan dengan penelitian ini, penulis mengadakan observasi terhadap mahasiswa beberapa kali. Penulis sebagai pengajar pada kelas mereka memiliki kesempatan yang cukup banyak untuk bisa menilai kemampuan mereka dalam menulis tulisan Arab.

Untuk itu, dengan penelitian ini, penulis berharap dapat mengetahui kesalahan-kesalahan berbahasa lebih lanjut khususnya dalam aspek kesalahan penulisan kata (al-akhtha' al-imlaiyyah) yang dilakukan oleh mahasiswa PAI semester I kelas A, B, C, dan F di IAIN Syaikh Abdurrahman Siddik Bangka Belitung. Penelitian ini diharapkan bisa menjadi dasar pengembangan media ataupun metode pembelajaran tahsinul kitabah ataupun maharotul kitabah, sehingga mahasiswa yang memiliki keterbatasan dalam kemampuan menulis Arab bisa mengejar ketertinggalan mereka dengan mahasiswa lainnya.

\section{Metode}

Penelitan ini merupakan penelitian kualitatif deskriptif dimana penulis akan memaparkan bentukbentuk kesalahan yang sering dilakukan oleh mahasiswa tersebut dalam menulis kata-kata tulisan Arab. Untuk mengumpulkan data penelitian dilakukan dengan cara observasi, dokumentasi dan wawancara dengan para mahasiswa. Data tersebut kemudian direduksi, dianalisis dan kemudian disimpulkan untuk memperoleh informasi yang tepat.

\section{Hasil dan Pembahasan}

\section{Kesalahan Berbahasa}

Kesalahan berbahasa atau dalam bahasa Arab dikenal dengan istilah (al-akhtha' allughowiyyah) diartikan sebagai penyimpangan dari standar bahasa yang baik dan benar sesuai dengan penutur asli.(Thu'aimah, 2004) Beberapa aspek kesalahan berbahasa yang sering dilakukan meliputi aspek struktural (akhtha' tarkibiyyah), aspek morfologis (akhtha' sharfiyyah), aspek semantis (akhtha' dalaliyyah), dan aspek penulisan kata (Akhtha' Imlaiyyah).(Wahab, 2008)

\section{Kesalahan Penulisan Kata (al-Akhtha' al-Imlaiyyah)}

Kesalahan penulisan kata disini merupakan kesalahan dalam menulis huruf-huruf tertentu, baik terkait dengan cara menyambungkannya, maupun memisahkannya. Imla' sendiri terdiri dari beberapa jenis, yaitu:

a. Imla' manquul: yaitu menyalin atau memindahkan tulisan ke dalam buku dari media tertentu.

b. Imla' manzhur: yaitu menyalin bacaan tertentu yang sudah dibaca, namun siswa tidak diperkenankan lagi untuk melihat kembali tulisan bacaan tersebut.

c. Imla' ghairu manzhur: yaitu menulis bacaan yang dibacakan oleh guru, dalam artian siswa tidak boleh melihat tulisan tersebut dari media lain. (Rahmi, 2016)

\section{Problematika dalam Pembelajaran Bahasa Arab}

Menulis merupakan salah satu dari kemahiran berbahasa Arab. Sedangkan imla' adalah salah satu bentuk dari kemahiran menulis. Problematika yang muncul dalam pembelajaran bahasa Arab mencakup problematika linguistik dan non linguistik. (Hermawan, 2011) Problematika linguistik berkaitan dengan aspek bahasa secara langsung, sedangkan problematika non linguistik berkaitan dengan aspek non bahasa.(Asyrofi, 2010) 


\section{Bentuk-bentuk Kesalahan Penulisan Kata pada Mahasiswa PAI Kelas A, B, C, dan F IAIN SAS} Bangka Belitung

Dari hasil penelitian yang penulis lakukan terhadap hasil kerja mahasiswa dalam penulisan kata (imla') dapat dijelaskan sebagai berikut:

\section{a. Kesalahan dalam penulisan bentuk huruf hijaiyah}

Yang dimaksud disini adalah kesalahan penulisan bentuk huruf hijaiyah dalam hal bentuk atau ukuran huruf hijaiyah sehingga menyebabkan huruf-huruf tersebut mirip dengan huruf lainnya.

Contoh:

\begin{tabular}{|c|c|c|}
\hline No & Salah & Benar \\
\hline 1. & بِيل & بَدِيْلِّ \\
\hline 2. & سََـارَ & سَارَ \\
\hline
\end{tabular}

Pada contoh pertama, beberapa mahasiswa menulis huruf د dengan ukuran yang lebih besar sehingga tidak seimbang dengan ukuran huruf yang lainnya. Hal tersebut berakibat timbulnya kesalahan dalam membaca hasil tulisan sendiri. Pada kata بَبَيْيُ , huruf د tampak seperti huruf $J$, sehingga dibaca menjadi baliilun. Dalam contoh lain, penulisan huruf $د$ juga sering ditulis mirip dengan huruf $\lrcorner$.

Pada contoh kedua, jarang kita memperhatikan kesalahan dalam penulisan huruf ش ,

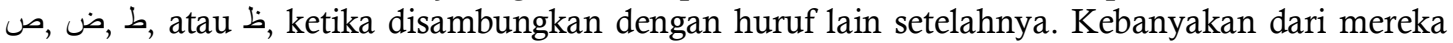
menulis huruf tersebut dengan menambahkan bentuk/garis yang berlebihan. Dalam contoh di atas, misalnya kata سَّارَ menjadi. Contoh lain, kata صَارَ menjadi صَامَ dan lain-lain. Penulisan tersebut menyebabkan tampak ada tambahan huruf $\mathrm{s}$.

Kesalahan dalam aspek ini merupakan kesalahan yang sangat dasar, dengan arti bahwa kemampuan ini adalah kemampuan dasar yang harus dimiliki oleh seseorang agar bisa menulis tulisan Arab pada tingkatan selanjutnya. Penyebab lemahnya kemampuan mahasiswa dalam bidang ini adalah dikarenakan mahasiswa tersebut jarang menulis tulisan Arab ataupun membaca tulisan Arab.

b. Kesalahan dalam menulis ta' marbuthah (ث) dan ta' maftuhah (ت) Contoh:

\begin{tabular}{|c|c|c|}
\hline No & Salah & Benar \\
\hline 1. & مِسنطَرَتُ & مِنسطرَةٌة \\
\hline 2. & بَيْةُ & بَيْتُ \\
\hline
\end{tabular}

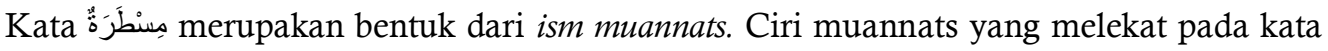
tersebut adalah adanya huruf ta' marbuthah. Adapun sebagian mahasiswa menulisnya dengan $t a$ ' maftuhah (ت) . Sedangkan sebaliknya, pada kata بَ بَ , sebagian mahasiswa menulisnya dengan menggunakan ta' marbuthah. Menurut penulis hal tersebut dikarenakan kebanyakan mahasiswaa belum familiar atau tidak terbiasa membaca kata-kata berbahasa Arab.

c. Kesalahan dalam menulis panjang pendek bacaan Contoh:

\begin{tabular}{|c|c|c|}
\hline No & Salah & Benar \\
\hline 1. & غَسِقُ & غَاسيقُ \\
\hline 2. & يَغْزُا & يَغَزُزٌ \\
\hline
\end{tabular}




\begin{tabular}{|c|c|c|}
\hline 3. & شَدِدِد & شَدَيْدُ \\
\hline
\end{tabular}

Pada saat mendikte kata غَاسِقِ penulis menekankan lafazh huruf ghain yang berharokat fathah yang berarti huruf tersebut dibaca panjang. Namun dalam hal ini seringkali sebagian mahasiswa tidak bisa membedakan panjang pendek tekanan bacaan yang penulis sampaikan. Hal ini kemudian penulis tindak lanjuti dengan mengetes beberapa mahasiswa yang bersangkutan untuk membaca Al-Qur'an. Hasil yang penulis temui adalah bahwa mahasiswa tersebut juga memiliki kekeliruan dalam membaca kalimat yang mengandung hukum bacaan mad.

Pada contoh nomor dua, penulis mendiktekan lafazh huruf يَغْزُوْ dengan memberikan tekanan pada huruf ghain yang berharokat dhammah. Namun beberapa mahasiswa menulis bacaan panjang setelah huruf berharokat dhommah dengan tambahan huruf alif, bukan huruf wawu. Hal ini dikarenakan para mahasiswa belum bisa membedakan bagaimana cara menulis bacaan mad dari suatu kata.

Pada contoh ketiga, kata شَنَدِدِ Hal ini juga disebabkan karena mahasiswa belum bisa membedakan pelafalan panjang pendek suatu bacaan yang didiktekan oleh penulis, dan tidak bisa membedakan bagaimana cara menulis bacaan mad dari suatu kata.

d. Kesalahan dalam mengidentifikasi bunyi huruf-huruf hijaiyah

\begin{tabular}{|c|c|c|}
\hline No & Salah & Benar \\
\hline 1. & سَنَاءٌ & تَنَاءٌ \\
\hline 2. & يَتَثُوْنُ & يَصَُونُ \\
\hline 3. & فُتِبَب & كُتِبَ \\
\hline
\end{tabular}

Dalam bahasa Arab dikenal dengan istilah makharijul huruf, yakni tempat keluarnya huruf-huruf hijaiyah. Untuk mengucapkan bahasa Arab, kita harus bisa membedakan antar huruf hijaiyah tersebut, karena jika kita melakukan kesalahan dalam melafalkan, maka akan mengakibatkan kekeliruan pula dalam penulisan maupun artinya.

س، ش، ث، dan lainnya. Di antara contoh kesalahan yang dilakukan adalah penulisan kata

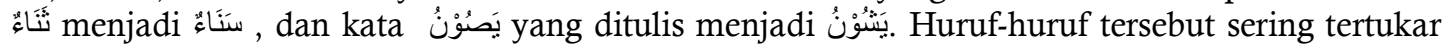

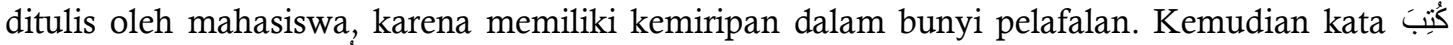

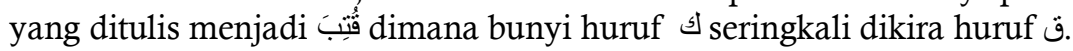

e. Kesalahan dalam menulis tanwin

\begin{tabular}{|c|c|c|}
\hline No & Salah & Benar \\
\hline 1. & ضَتِّقُشْنُ & ضَيَقِّ \\
\hline 2. & سَوِيّة & سَوَيًا \\
\hline
\end{tabular}

Bunyi tanwin memang mirip dengan bunyi nun sukun. Hal ini pula yang menyebabkan para mahasiswa kesulitan membedakan penulisan kata yang berharokat tanwin seperti kata dengan kata yang memang berakhiran dengan nun sukun, seperti أُنْكُنْ . Hal ini disebabkan karena penguasaan mahasiswa akan bahasa Arab yang minim.

Pada contoh kedua, kata سَوِِيَّة ditulis oleh mahasiswa menjadi. Pada kasus ini memang sudah benar bahwa iya sudah menulis tanda tanwin, namun tidak menambahkan lagi huruf alif setelahnya. Hal ini juga disebabkan oleh ketidaktahuan mahasiswa tentang penulisan kalimat bahasa Arab yang benar.

f. Kesalahan dalam menulis tasydid

\begin{tabular}{|c|c|c|}
\hline No & Salah & Benar \\
\hline 1. & سوَيٌّ \\
\hline
\end{tabular}




\begin{tabular}{|c|}
\hline 2. \\
\hline
\end{tabular}

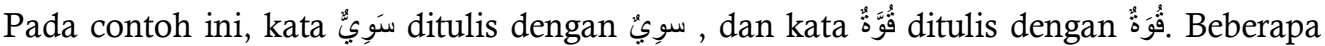
penyebab hal ini adalah mahasiswa tidak bisa membedakan pelafalan penulis saat melafalkan huruf yang bertasydid yang dibaca dengan memberikan tekanan pada huruf yang bertasydid.

g. Kesalahan dalam menyambung huruf-huruf

\begin{tabular}{|c|c|c|}
\hline No & Salah & Benar \\
\hline 1. & نَسِ يَّ & نَبِيَ \\
\hline 2. & حَكِيْ مُ مُ & حَكَيْمِ \\
\hline
\end{tabular}

Dalam tulisan Arab, kita mengetahui bahwa terdapat huruf-huruf yang bisa ditulis secara bersambung saat ia merupakan satu kata sempurna, dan terdapat pula huruf-huruf yang tidak bisa saling bersambung dengan huruf lainnya. Beberapa huruf bisa disambung dengan huruf sebelumnya, tetapi tidak bisa disambung dengan huruf setelahnya. Namun ada pula huruf yang bisa disambung dengan huruf sebelumnya, maupun dengan huruf sesudahnya.

Terkait hal ini, masih banyak mahasiswa yang belum mengetahui sepenuhnya bagaimana menulis kalimat dalam bahasa Arab. Contohnya, kata خ حكيّم yang bisa ditulis bersambung semua, ditulis oleh mereka menjadi كَكِيْ مُ . Padahal seharusnya huruf ya'bisa ditulis bersambung dengan

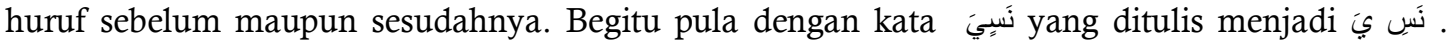
Seharusnya huruf tersebut bisa disambungkan baik dengan huruf sebelumnya maupun huruf sesudahnya.

h. Menghilangkan Lam Syamsiyah

\begin{tabular}{|c|c|c|}
\hline No & Salah & Benar \\
\hline 1. & آسَسَّكَكُ & آلَسَََّكَكُ \\
\hline 2. & آَثََّّمُسُ & آلَثََّّمُسُ \\
\hline
\end{tabular}

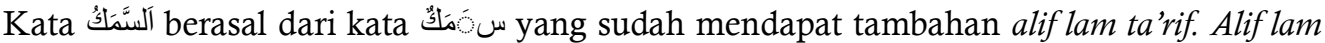
ta'rif sendiri dibagi menjadi dua, yaitu alif lam syamsiah dan alif lam qomariyah. Alif lam syamsiah adalah hukum pembacaan alif lam yang apabila bertemu dengan huruf-huruf syamsiah, maka bunyi huruf lam dimasukkan atau diidghamkan ke dalam huruf syamsiah, namun tanpa menghilangkan penulisan huruf alif lam. Sedangkan alif laf qomariyah adalah kebalikannya, yakni hukum pembacaan aliflam tetap dibaca dengan jelas.

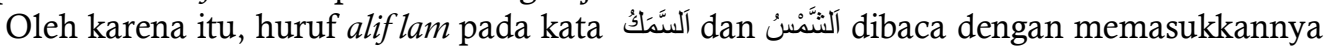
ke dalam huruf $\sin$ dan syin, sehingga menjadi "As-Samaku" dan "Asy-Syamsu", dan tetap ditulis

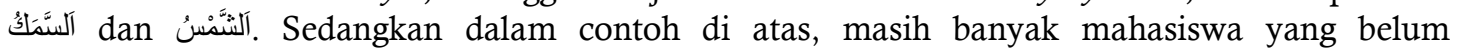
memahami cara menulis kata yang mengandung aliflam syamsiah. Hal ini pula disebabkan karena mahasiswa belum familiar dengan tulisan Arab.

\section{Solusi yang ditawarkan}

Dari analisis yang penulis sampaikan di atas, kita dapatkan beberapa penyebab terjadinya kesalahan dalam penulisan kata (akhtha' imlaiyah) yang dilakukan oleh mahasiswa PAI semester I kelas A, B, C, dan F pada IAIN Syaikh Abdurrahman Siddik Bangka Belitung yaitu pada aspek linguistik mereka belum terbiasa membaca atau menulis tulisan Arab sehingga mereka belum familiar dengan tulisan Arab. Selain itu, mereka juga banyak yang belum pernah belajar tentang bagaimana cara menulis huruf hijaiyah yang baik dan benar. Sedangkan dari aspek non linguistik, disebabkan oleh latar belakang pendidikan mereka sebelumnya yang berasal dari sekolah umum yang memiliki sedikit jam pelajaran untuk pelajaran-pelajaran agama. Selain itu, juga dikarenakan lingkungan keluarga yang kurang mendorong para mahasiswa untuk belajar ilmu-ilmu agama di pendidikan non formal selain di sekolah. 
Berdasarkan hal tersebut, penulis menawarkan beberapa solusi sebagai berikut:

a. Bagi para pengajar agar memberikan tes awal terlebih dahulu pada awal semester agar bisa mengetahui tingkat kemampuan mahasiswa dalam menulis tulisan Arab.

b. Setelah mengetahui hasil tes tersebut, pengajar hendaknya menyusun materi pelajaran sesuai dengan tingkat kemampuan mahasiswa tersebut. Bagi mahasiswa yang memiliki kemampuan yang cukup bagus, materi yang diberikan bisa menyesuaikan agar ia tidak jenuh dengan materi yang sudah mereka kuasai.

c. Pengajar hendaknya fasih dan cermat dalam mengajarkan imla' ini kepada mahasiswa.

\section{Kesimpulan}

Berdasarkan pemaparan di atas dapat penulis simpulkan bahwa kesalahan penulisan kata mahasiswa PAI kelas A, B, C, dan F semester I Tahun Ajaran 2019/2020 meliputi kesalahan dalam penulisan bentuk huruf hijaiyah, penulisan ta' marbuthah dan $t a^{\prime}$ maftuhah, penulisan panjang pendek bacaan, pengidentifikasian bunyi huruf-huruf hijaiyah, penulisan kata bertanwin dan bertasydid, menyambung huruf, dan alif lam syamsiah. Hal tersebut di antaranya disebabkan oleh kurangnya kemampuan mahasiswa terkait bagaimana cara menulis tulisan Arab yang benar, dikarenakan kebanyakan dari mereka berasal dari sekolah dengan sedikit jam belajar tentang pendidikan agama Islam.

\section{Referensi}

Asyrofi, S. (2010). Metodologi Pembelajaran Bahasa Arab. Yogyakarta: Idea Press.

Hamid, A. (2010). Mengukur Kemampun Bahasa Arab untuk Studi Islam. Malang: UIN-Maliki Press.

Hermawan, A. (2011). Metodologi Pembelajaran Bahasa Arab. Bandung: PT. Remaja Rosdakarya.

Rahmi, N. (2016). Pengembangan Materi Qowaid al Imla' Sebagai Penunjang Mata Kuliah Kitabah I ( Studi pada Mahasiswa Jurusan PBA Fakultas Tarbiyah IAIN Metro ), 20(01).

Syamsiyah, B. (2019). Analisis Kesalahan Berbahasa dalam Imla 'Mahasiswa IAIN Salatiga, 21-44.

Thu'aimah, R. A. (2004). al-Mahaarat al-Lughawiyyah, Mustawayatuha wa Tadrisuha wa Shu'ubatuha. Darul Fikr al-'Arabiy.

Wahab, M. A. (2008). Epistemologi dan Metodologi Pembelajaran Bahasa Arab. Jakarta: UIN Jakarta Press. 